Portland State University

PDXScholar

1974

\title{
Personality characteristics, work practices, and error rates among welfare assistance workers at East Multnomah County Public Welfare Branch
}

\author{
Roy Dale Beams \\ Portland State University \\ Mike David Gotesmen \\ Portland State University \\ Howard Wayne Knytych \\ Portland State University
}

Follow this and additional works at: https://pdxscholar.library.pdx.edu/open_access_etds

Part of the Industrial and Organizational Psychology Commons, and the Social Work Commons Let us know how access to this document benefits you.

\section{Recommended Citation}

Beams, Roy Dale; Gotesmen, Mike David; and Knytych, Howard Wayne, "Personality characteristics, work practices, and error rates among welfare assistance workers at East Multnomah County Public Welfare Branch" (1974). Dissertations and Theses. Paper 1752.

https://doi.org/10.15760/etd.1751

This Thesis is brought to you for free and open access. It has been accepted for inclusion in Dissertations and Theses by an authorized administrator of PDXScholar. Please contact us if we can make this document more accessible: pdxscholar@pdx.edu. 


\title{
PERSONAIITY CHARACTERISTICS, MORK PRACTTCES, AND ERROR RATES \\ AMONG WELFARE ASSISTANCE WORKERS \\ AT EAST MUITNOMAH COUNTY. PUBIIC WEIFARE BRANCH
}

\author{
by \\ ROY DAIE BEAMS " \\ MIKE DAVID GOTESMAN \\ HOWARD WAYNE KNYTYCH
}

A practicum submitted in partial fulfillment of the
requirements for the degree of

MASTER OF SOCIAI, WORK

Portland State University 1974 
TO THE OFFICE OF GRADUATE STUDIES AND RESEARCH:

The members of the committee approve the practicum of Roy Dale Beams, Mike David Gotesman, and Howard Wayne Knytych presented May 10,1974.

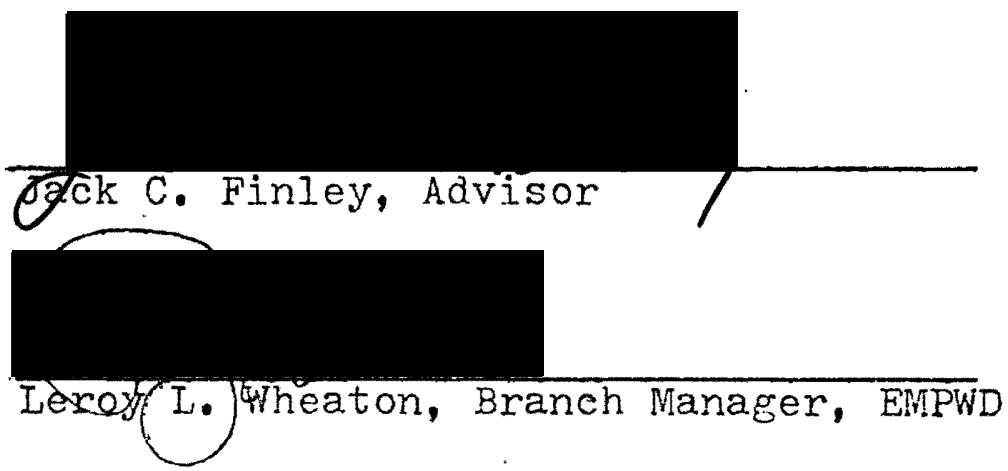




\section{ACKNOWLEDGMENTS}

We wish to thank Mr. Iarry Wheaton, Branch Manager of East Multnomah County Public Welfare, for his permission and enthusiasm which helped us undertake this study, and for his continued advisory support and interest. Mr. Alvin Damm, Unit Supervisor at the East County Branch, diverted considerable time from his regular supervisory duties to offer us indispensible technical advice and guidance. We are greatly indebted to him. Finally, the assistance workers who were the focus of this study offered us their time, patience, cooperation, trust, and charm. The particular warmth we received from them helped make this study a fulfilling experience for all three of us. 
TABLE OF CONTENTS

PAGE

APPROVAL PAGE. . . . . . . . . . . . . . i i ACKNOWLEDGEMENTS ................... . . i ii IIST OF TABLES ............. . . . . v v

INTRODUCTION..................... 1 APPROACH . . . . . . . . . . . . . . 3 NETHODOLOGY. . . . . . . . . . . . . . 5

Error Rates . . . . . . . . . . 5

Criteria for not Reviewing a Case. . . . . 6 Definition of Error. . . . . . . . . : 8 Procedure. . .............. 9

Personality Factors ........... 10

Work Sampling . . . . . . . . 13

FINDINGS . . . . . . . . . . . . . . 19

Error Rates . . . . . . . . . . . 19

. Personality Factors ......... 2 24

Work Sampling . . . . . . . . . . 29

Correlations of Work Sampling Data and CPI Scores . 33 CONCLLSIONS. . . . . . . . . . . . . . . . 35 IMPLICATIONS AND RECOMMENDATIONS . . . . . . . 37 BIBLIOGRAPHY . . . . . . . . . . 44 APPENDIX ........................... 45 


\section{IIST OF TABIES}

\section{TABLE}

PAGE

I Case Review Selection Statistics. . . . . . 7

II Case Reviewer Comparison. . . . . . . . . 22

II Caseload Comparison . . . . . . . . . 23

IV General Profile of CPI Factor Scores. . . . . 26.

$\mathrm{V}$ Class Breakdown of CPI Factor Scores. . . . . 27

- VI Group Summary Statistics. . . . . . . . . 28.

VII Work Sampling Summary Statistics. . . . . . 30

VIII Correlations of Work Sampling Activities. . . 31

IX Correlations of Work Activities and CPI Scores. $\quad 34$ 


\section{- INTRODUCTION}

The research project herein contained was an outgrowth of concern associated with performance levels placed upon Welfare Assistance Workers (WAW's). The Oregon State Public Welfare Division has become increasingly concerned with accuracy rates among branch offices throughout the system. It was the impression of the research group that WAW's see this increased concern as combined pressure to reduce error rates and demand for a broajer diversity of skills. For example, OSPWD directs WAW's in branch offices to lower ineligibilities to $3 \%$ and, at the same time, decrease overpayments to $5 \%$ (I). AIso, WAW's have been required to initiate manditory referrals to the Work Incentive and Training Program (WIN), and, in some counties, to assess and establish eligibility for food stamps in households where Public Assistance (GA Standards) and non-recipients reside together. "In the service of brevity, additional examples of broadened iob expectations will not be listed though evidence is readily available.

We do not question the importance of accuracy or error rates as indices of work performance. However, based upon observations prior to this study, we believe the WAW position evolved by administrative directives without benefit of accurate assessment of personnel characteristics or current methods of caseload management. We believe the latter to be essential 
inclusions in evaluating worker performance as well as determining job expectations.

The primary purpose of this study was to explore ways of clarifying indiyidual characteristics and work habits and their relationship to error rates in the WAW's in the East Multnomah County Branch Office of PWD. Our hypothesis was that a relationship exists among individual personality characteristics, work practices, and error rates. A secondary purpose of the study was to develop a conceptual framework which might suggest methods of personrel management or employment screening for WAW positions. 


\section{- APPROACH}

One member of the research team had been employed during the summer of 1973 in the East Multnomah County branch office of PWD. This office was subsequently selected as the site for our study due to the interest and cooperative efforts of the branch manager and the receptive employees who were interested and accessable to the research team.

The unit of study consisted of nine AW's in one supervisory unit who had responsibility for ongoing eligibility determination in the Aid to Families with Dependent Children (AFDC) category. The basis for selection of this unit and "category" was several fold: First, it is the largest single category of assistance. Additionally, it is the most closely scrutinized by PWD and seems to receive most of the anger the public directs toward PWD.

The researchers utilized a "review system" in process at EMPWD at the time of the study. This review system cont sisted of a case-by-case eligibility revi conducted by six employees at the branch office. It appeared to be the only reliable gauge of actual performance errors in caseloads. Thus, the study served an additional purpose of evaluating the existing review process.

A standardized personality inventory was employed to obtain an assessment of selected individual personality 


\section{. METHODOLOGY \\ I. ERROR RATES}

Total case review was the method selected to identify error rates. We intended to review all cases contained in all nine caseloads of the selected supervisory unit. However, limitations of agency staff time, research team availability, and changes in the internal office structure allowed review." of only five" caseloads.. Total review of all" the caseloads would have involved a greater expenditure of time than was available. The caseloads finally selected were a result of two significant factors: the number of basic AFDC cases in the caseloads, and the order in which the WAW's volunteered to have their loads reviewed. The selection process was not random, and we realize that having the WAW's volunteer their caseloads for review may have introduced bias. Presumably,... the bias would result in lower error rates, as workers may have "cleaned up" their caseloads prior to review. A mediathing factor, we belieyed swas that-those-workers; who volunteered were concerned with inaccuracy in some of their cases and expressed a desire for help in putting them in order.

Accepting volunteered caseloads had practical advantages. The functioning of the unit was less disrupted, and the goodwill and sanction of the assistance workers was promoted. Initial support resulted from the WAW's desire for adminis- 
trative personnel to have more accurate information upon which to assess their performance. One caseload was designated as a "training caseload," and consisted of clients who were less mobile and more economically stable. Workers who were new appointees or less experienced were responsible for this load. It was felt that review of this load would not give an accurate picture of worker functioning. Five caseloads of the remaining eight were carefully screened im the order they were volunteered. Those five loads selected contained a total . of 745 cases. The caseload sizes ranged from 126 to 184 cases. of the 745 cases, 606 received a full review. Of the remaining 139 cases not reviewed, 116 did not meet criteria for the study. The remaining 23 cases were missed because the case files were not available. These 23 cases missed represent $3.08 \%$ of the total cases (see Table I).

\section{Criteria for not Reviewing a Case}

116 cases were not reviewed for the flollowing reasons: 1. Receipt of assistance for 3 months or less. These cases were reviewed at the time of intake. Inaccuracy of payment was unlikely unless present at the time of intake. Potential for discovery by ongoing assistance worker was very low. (35 cases)

2. Recent home visit or reinvestigation by the assis-.. tance worker lent confidence in the accuracy of the case. ( 30 cases)

3. Cases in which the recipient had requested closure 
TABIE I

CASE REVIEW SELECTION STATISTICS

\begin{tabular}{|c|c|c|c|c|c|c|c|c|}
\hline Caseload & $\begin{array}{l}\text { Total } \\
\text { Reviewed }\end{array}$ & $\begin{array}{c}\text { No } \\
\text { Errors }\end{array}$ & Closed & Errors & $\begin{array}{c}\text { No reason } \\
\text { Missing }\end{array}$ & $\begin{array}{l}\text { Meets } \\
\text { Criteria } \\
\text { for } \\
\text { Missing }\end{array}$ & $\begin{array}{r}\text { Total } \\
\text { Missed. }\end{array}$ & $\begin{array}{c}\text { Caseload } \\
\text { Total }\end{array}$ \\
\hline - & & & & & & & & \\
\hline 2 & 138 & 103 & 6 & 29 & 2 & 15 & 17 & 155 \\
\hline$?$ & 132 & 102 & 2 & 28 & 2 & 12 & 14 & 146 \\
\hline 8 & 115 & 91 & 7 & 17 & 6 & 13 & 19 & 134 \\
\hline 6 & 64 & 35 & 11 & 18 & 6 & 56. & 62 & 126 \\
\hline 3 & 157 & 134 & 2 & 21 & 7 & 20 & 27 & 184 \\
\hline Totals & 606 & 465 & $28 *$ & 113 & 23 & 116 & 139 & 745 \\
\hline
\end{tabular}

*28 cases closed for miscellaneous reasons. Assumed correct at time of closure. These $2.8+465$ iwth no errors $=493$ correct cases reviewed 
of the grant due to factors not related to the case review process. (26 cases)

4.- Step-father grants in which only the step-children received assistance. These cases were reviewed only if inaccuracies or conflict of information was moted in case record. (10 cases)

5. Cases in the process of transfer to another branch. office due to change of residence by recipient. ( 6 cases)

6. Cases in a state of suspension the time of $\cdots ?$ "review. No money payments were being made. (3 cases)

7. Cases with court action pending at time of review. ( 3 cases)

8. A case in which neither parent the child is in the home. Example: grandparents getting financial assistance for dependent grandchildren. (1 case)

9. A case in which the recipient acepted medicaid' only. No money payment was made: $\because(1$. case) )

$\because$ 10. A. case in which an error was known and was being referred for clarification, investigation, prosecution. ( 1 case)

\section{Définition of Error}

The standard eligibility criteria for receipt of Public Welfare funds were considered when the casr reviewer made a home visit with a client. For the purpose of this study, no distinction is made among the types and aunts of errors in a case. : An error was defined as either an underpayment, an 
overpayment, ineligibility, or a combination of them. In keeping with PWD guidelines, a case was considered equally defective if it had one error or if it had many. our desire was to count defective cases and not the number of defects in a case.

In 28 cases, when the reviewer made contact with the recipient, the recipient requested that the assistance be closed. The reasons offered by recipients included acquired employment, reconciliation with estranged husband, and signifcant changes in financial circumstances. When closure oc-' ' curred, the case review was suspended with the assumption that, at closure, the case was accurate in the amount of payment. For our purposes, these cases were considered to have no errors.

Any case that reflected a money payment which was more than \$5.00 different from the appropriate amount as determined by Welfare standards or which showed an overpayment to the recipient during the current or preceeding months was considered to be in error.

\section{Procedure}

Six employees (including four welfare assistance specialists, one 90-day temporary employee, and one regular assistance worker) proceeded through the caseloads, alphabetically selecting cases, reviewing records, making home visits, and verifying obtained information. The cases selected were by a rotation method. The reviewer would select a group of 
cases (ranging from five to twelve cases), review them, and return to the caseload to gather another group for review. Availability of the clients and other job demands of the reviewer determined the speed with which examination of a group of cases was completed. The process prevented any particular reviewer from pre-determining the names of the clients whose eligibility that reviewer would validate. The number of cases selected from each caseload varied from reviewer to reviewer. Individual reviewers did not participate in investigation of all five caseloads.

The range of total cases reviewed varied from 23 cases by one reviewer to 155 cases by another reviewer.

\section{PERSONALITY FACTORS}

The decision to use the California Personality Inventory (2) was predicated upon a study of appropriate personality tests and consultation with Mr. William I. Murphy, Psychologist, a specialist in vocational and occupational testing. As stated by the CPI, the "inventory" scales addressed themselves to "personality characteristics important for social living and social interaction and could be used with non-psychiatrically disturbed individuals." The CPI was developed by Harrison G. Gough and was copyrighted by Consulting Psychologists Press, Inc: in 1957.

Each of the eighteen scales of the CPI considers one aspect of personality. The scales can be arranged into four different categories or classes. The following is a breakdown 
of each of these classes and their relevant scales, including definitions :

Class I. Measures of Poise, Ascendancy, Self-Assurance, and Interpersonal adequacy.

1. Do Dominancy--Measuring lominancy, persistence, social initiative and leadership qualities.

2. Cs Capacity for Status-- index of capacity for status (not his actual or achieved status). The scale attempts to measure the personal qualities and attributes .which underlie or lead to status.

3. Sy Sociability--To identify persons of outgoing, sociable, participative temperament.

4. Sp Social Presence--To assess factors such as poise, spontaneity, and self-confidence in personal and social interaction.

5. Sa Self-Acceptance--To assess factors such as sense of personal worth and capacity for independent thinking and action.

6. Wb Sense of Well-Being--To identify persons who minimize their worries and complaints, and who are relatively free from self-doubt and disillusionment.

Class II. Measures of Socialization, Maturity, Responsibility, and Intrapersonal Structuring of Values.

7. Re Responsibility--To idemtify persons of conscientious, dependable disposition and temperament. 8. So Socialization-To indimate the degree of social maturity, integrity, and rectitude wich the individual 
has attained.

9. Sc Self-Control--To assess the degree and adequacy of self-regulation and freedom from impulsivity and selfcenteredness.

10. To Tolerance--To identify persons with permissive, accepting, and non-judgemental social beliefs and attitudes.

11. Gi Good Impression--To identify persons capable of creating a favorable impression and who are concemed about how others react to them.

12. Cm Communality--To indicate the degree to which reactions and responses correspond to the modal (common) pattern established in the inventory.

Class III. Measures of Achievement Potential and IntelIectual Efficiency.

13. AC Achievement via Conformance-To identify those factors of interest and motivation which facilitate: achievement in any setting where conformance is a positive behavior.

14. Ai Achievement via Independence--To identify those factors of interest and motivation which facilitate: achievement in any setting where autonomy and independence are positive behaviors.

15. Ie Intellectual Efficiency--To indicate the degree of personal and cognitive efficiency which has been attained. 
Class IV. Measures of Intellectual and Interest Modes.

16. Py Psychological-Mindedness--To measure the degree of interest in and response to the inner needs, motives, and experiences of others.

17. Fx Flexibility--To indicate the degree of flexibility and adaptability in thinking and social behavior. 18. Fe Femininity--To assess the masculinity or femininity of interests. High scores indicate more feminine interests; low scores, more masculine (4).

The assistance workers response sheets were scored manually as prescribed by the CPI manual.

\section{WORK SAMPLING}

The unit supervisor and branch manager indicated a desire to learn how workers invest their time on the job-activities in which they are involved and how much time they spend in these activities-in short, what could be called the workers" "styles" of working. They wanted to know, if possible, what bearing the workers' activities had upon the accuracy of their caseloads. We chose a time study $(5,6)$ approach as a measure of individual. activity style. The design task was difficult because we found little in the literature on measuring complicated tasks such as welfare assistance work, where decision-making and interpretation of policy are common. Most designs seemed to be time and motion studies of simple or repetitive functions, such as production work. Other somewhat arbitrary but necessary decisions by the research team 
included how long a period to sample the unit, how closely would the WAW's be monitored, and how minutely we would distinguish their activities, given the research manpower at our disposal.

To particularize procedures to the unit of study, we held conferences with several of the workers and simply asked what they did. We then drew up a list, adding our own expectations and knowledge of what they did gained from work experience, observations, and job descriptions. After the confer" ences we drew up a paradigm of" all the sigmificant activities. Since an important focus of the research on personality, and because workers estimated that a major portion of their jobs involved communication with clients, office staff, and others, the paradigm was divided into three groups: The first, "communication activity," included Il forms of communication, such as phone contacts with cï̈ients, field interviews, letters, etc. In addition, we cod responses to indicate whether the communication was workm-initiated or other-initiated. There were twelve forms of communication activity in this group. The second group discerned the intent of a worker's communication. If she were flound communicating in some fashion, her intent, such as passämg information, verifying, instructing, etc., would be coded. Also coded were responses to indicate the direction the commurication, i. e., whether the worker was giving information or receiving it. There were eight forms of intent, plus an additional "other" form. The third group consisted specific activities 
which may or may not have included communication, such as budget actions, reading case material, transportation, coffee break, etc. We decided to start with fifty activity categories, including a general "other" category.

A week of sampling was conducted as a preliminary run to test the workability of our procedures. Numerous discussions among all three researchers and the unit supervisor took place as we observed behaviors which did nat fit into the fifty activity categories. Categories were further defined to include activities not previously included. We also found it necessary to add three more categories, bringing the total possibilities of classification to fifty-three. The fiftythree final categories seemed to cover all observed behaviors thoroughly. of the 1,365 observations, only 12, less than $1 \%$, were coded in the catchali, "other," category. Four of the categories, including "fair hearings" and "4700 actions (tax returns)," were not used at all. For the purpose of data collection, a work sheet of activities was employed for each worker and coordinated with observation times (see page $I$ of the Appendix).

We decided to sample the nine workers' activities from September 11 through October 9, 1973, a total of twenty working days. We recognize that our. "run" of observations covering a one-month period from mid-September to mid-october does not account for seasonal fluctuations in worker activity. We monitored each worker once during each working hour (for a. total of $8 \times 20=160$ possible samples per worker) in random 
order and at random times. This was done by assigning each worker a number at random; then ranking those assigned numbers in random sequence from a table of random numbers for each working hour. Finally, random times within the hour were ascertained by choosing pairs of random rumbers and converting them to minutes. Thus each worker sampled once during every working hour to account for däly fluctuations, but the order and times were randomized to prevent bias. We were unable to monitor the workers' activities in ' the field or in office interviews with clinents. Thus we were Iimited to the workers' recollections of Hineir activity in the field at sample times. The reporting was made easier, and presumably more reliable by the local requirement that workers maintain a time $\log$ of field interwiews, identifying clients and when they were seen. The log was far less specific than our research requirements, but it was an aid. Workers were informed of our requirements and appeared to keep fairly accurate tabulations of their field activities. of the total samples gathered during the twemty working days, 246; or slightly more than 18\%, were worker-reported.

After the work sampling period, we relized many of the categories of activity or communication were so highly related that, even after conferences with the supervisor, the task of distinguishing them was difficult: For exmple, in communicating with a client, whether a worker was "werifying," "clarifying," or "seeking information" was oftem unclear. Aiso, many of the totals were too minute to be singnificant. Thus, 
the activities identified as communication, and communicative intent were grouped under the same category. After conferring with the unit supervisor and comparing the intent and useability of the data, we decided to modify all the response categories (thirteen communication, nine communicative intent, and fifty-three specific activity categories for a total of seventy-five) into nineteen broader areas. The thirteen communication activity categories were collapsed into eight larger areas accordingly: Phoning Clients, Phoning Others, Field Interviews, Office Interviews, Conferences, Meetings, Letter Writing, and No Communication for a negative response for the entire group. The nine communicative intent categories were similarly joined into four larger areas: Passing Information, Instructing and Directing, Reassuring or Ventillating, and Responding to Messages. The specific activity categores, finally, were merged accordingly:

- Thinking, Eligibility Interpretation, Medical Interpretation, Eligibility Determination, and Listening became Interpretation; Handwriting Letters, Writing Form Letters, $403 \mathrm{~B}$ Action, 437 Action, 138A Action, 409 Office Action, 408 Narrative Action, Grant Recomputation, 859A Report, 815A Action, School Allowance, 405B Action, Special Needs Action, Earnings Deductions, Checking 403B with Salem, Calling Salem for Checks, Food Stamp Activity, 459 Action, and 50\% of Comp. Time became Financial Manipulation; Dictating, QC Reports, UC Printouts, Collateral Calls, Transportation, 409 Field Actions, and 50\% of Comp. Time became Verification; WIN Referrals, WRD Refer- 
rals, Service Functions, CSD Referrals, and other Referrals became Referrals to Others; Reading Case Material, Filing, Transfer Actions, Opening, Closures, and Miscellaneous Office Activities became Housekeeping and Filing; Reading Manuals, Staff Training and Other Memos became Education; Coffee Break, Lavatory Break, and Personal Time became Personal Activities. All other categories of response were eliminated because the totals were insignificant. 


\section{FINDINGS}

\section{ERROR RATES}

In assessing the error rates and the variation in errors from caseload to caseload, we had to consider the consequences of having reviewers with different levels of expertise, experience, personality, and attitudes. We felt these factors - could prevent a realistic compárison of caseloads with one another.

A chi square test was used to compare the number of errors discovered between reviewers. In order to accomplish this, some standard had to be assumed. The ninety-day temporary employeets overali (caseload to caseload) average error rate of $20.149 \%$ was assumed as a standard. The rationale behind this decision included the following considerations: Although this employee had experience in eligibility determination, the experience occurred more than three years previously. This lag resulted in more consultation with the supervisor on eligibility questions. Higher accuracy was anticipated as a result of this consultation. As a temporary employee, this worker had no vested interests or biases in caseloads or in clients. He had no duties except for the case review process. 
The formula $x^{2}=\frac{\left(\mathrm{Fo}_{1}-\mathrm{Fe}_{1}\right)^{2}}{\mathrm{Fe}_{1}}+\frac{\left(\mathrm{Fo}_{2}-\mathrm{Fe}_{2}\right)^{2}}{\mathrm{Fe}_{2}}$ was used as a test of differences assuming one degree of freedom, where: $\mathrm{FO}_{1}=$ frequence of errors obtained, $\mathrm{Fe}_{1}=$ frequency of errors expected (compared with standard). Findings are shown in: Table 2. In Table 2 is the number of cases reviewed in each caseload by each reviewer, the $x^{2}$ of the variation of errors obtained to the errors expecict, and the level of confidence of the $x^{2}$ s obtained by the formula. It shauld be noted that in twenty-one comparisons with the standard, only in three comparisons did the significance exceed the .05 level of confidence. One was significant at the .01 level. Statistically, three significant differences in 21 comparisons could be due to chance. Therefore, we found no significant difference in the reviewer's rates of error discovery (7).

A contingency table based on a Chi square, goodness of fit, test with four degree of freedom was adapted as the means to compare variation of error rates from caseload to caseload. This comparison is shown in Table 3, where Fo= actual findings, $C=$ amount of assistance given correctly, $E=$ amount of assistance given in error, and $F e=$ frequency of expected correct and error cases found by multiplying column totals by row totals and dividing by 606 , the total number of cases reviewed. Fo - Fe was computed for both the number correct and the number in error. These were then squared and divided by $F e$ for both the number correct and the number in error. We then found $x^{2}$ by the formula: $x_{2}=\frac{(\mathrm{Fo}-\mathrm{Fe})^{2}}{\mathrm{Fe}}+$ 
$\frac{(\mathrm{FO}-\mathrm{Fe})^{2}}{\mathrm{Fe}}$. Since $\mathrm{X}^{2}$ is additive, a hypothesis involving more than one set of data can be tested for significance. With four degrees of freedom, an $x^{2}$ of 8.88 is not significant at the .05 level of confidence. We can state that the difference in errors found from caseload to caseload did not prove significant. 
TABLE II

CASE REVIENER COMPARISON

\begin{tabular}{|c|c|c|c|c|c|c|}
\hline 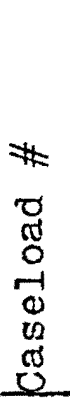 & 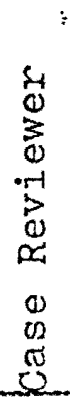 & 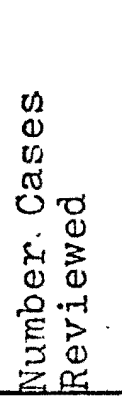 & 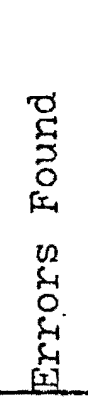 & 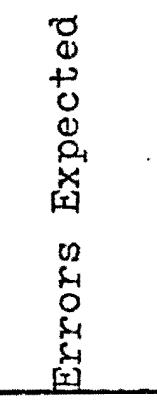 & $x^{2}$ & Levels of Significance \\
\hline 2 & $\begin{array}{l}1 \\
2 \\
3 \\
4 \\
5 \\
6\end{array}$ & $\begin{array}{r}27 \\
38 \\
34 \\
3 \\
23 \\
13\end{array}$ & $\begin{array}{r}11 \\
4 \\
8 \\
1 \\
4 \\
1\end{array}$ & $\begin{array}{l}5.4 \\
7.64 \\
6.83 \\
.6 \\
4.62 \\
2.6\end{array}$ & $\begin{array}{l}7.258 \\
2.17 \\
.250 \\
3.166 \\
.104 \\
1.231\end{array}$ & $\begin{array}{l}\text { Sig. at..01 level* } \\
\text { Not sig. at } .01 \text { level } \\
\text { Not sig. at } .50 \text { level } \\
\text { Not sig. at } .05 \text { level } \\
\text { Not sig. at } .70 \text { level } \\
\text { Not sig. at } .20 \text { level }\end{array}$ \\
\hline 7 & $\begin{array}{l}1 \\
2 \\
3\end{array}$ & $\begin{array}{l}57 \\
32 \\
43\end{array}$ & $\begin{array}{l}14 \\
-5 \\
-5\end{array}$ & $\begin{array}{r}11.46 \\
6.43 \\
8.64\end{array}$ & & $\begin{array}{l}\text { Not sig. at } .30 \text { level } \\
\text { Not sig. at }: 50 \text { level } \\
\text { Not sig. at } .80 \text { level }\end{array}$ \\
\hline 8 & $\begin{array}{l}1 \\
2 \\
3 \\
5\end{array}$ & $\begin{array}{l}25 \\
36 \\
17 \\
37\end{array}$ & $\begin{array}{l}4 \\
8 \\
2 \\
3\end{array}$ & $\begin{array}{l}5.03 \\
7.24 \\
3.4 \\
7.44\end{array}$ & $\begin{array}{l}.264 \\
.099 \\
.72 \\
3.316\end{array}$ & $\begin{array}{l}\text { Not sig. at } .50 \text { level } \\
\text { Not sig. at } .70 \text { level } \\
\text { Not sig. at }: 30 \text { level } \\
\text { Not sig. at } .05 \text { level }\end{array}$ \\
\hline 6 & $\begin{array}{l}1 \\
2 \\
4 \\
6\end{array}$ & $\begin{array}{r}46 \\
8 \\
9 \\
1\end{array}$ & $\begin{array}{r}15 \\
1 \\
2 \\
0\end{array}$ & $\begin{array}{l}9.26 \\
1.6 \\
1.8\end{array}$ & $\begin{array}{l}4.454 \\
.281 \\
.027\end{array}$ & $\begin{array}{l}\text { Sig. at } .05 \text { level* } \\
\text { Not sig. at }: 50 \text { level } \\
\text { Not sig. at }: 80 \text { level } \\
x^{2} \text { not calculated. }\end{array}$ \\
\hline 3 & $\begin{array}{l}2 \\
5 \\
4 \\
6\end{array}$ & $\begin{array}{l}32 \\
80 \\
11 \\
34\end{array}$ & $\begin{array}{r}3 \\
14 \\
2 \\
2\end{array}$ & $\begin{array}{r}6.4 \\
16.1 \\
2.2 \\
6.83\end{array}$ & $\begin{array}{r}2.258 \\
.343 \\
.023 \\
4.273\end{array}$ & $\begin{array}{l}\text { Not sig. at } .10 \text { level } \\
\text { Not sig. at } .50 \text { level } \\
\text { Not sig. at } .80 \text { level } \\
\text { Sig. at .05 level* }\end{array}$ \\
\hline
\end{tabular}


TABLE III

CASELOAD COMPARISON

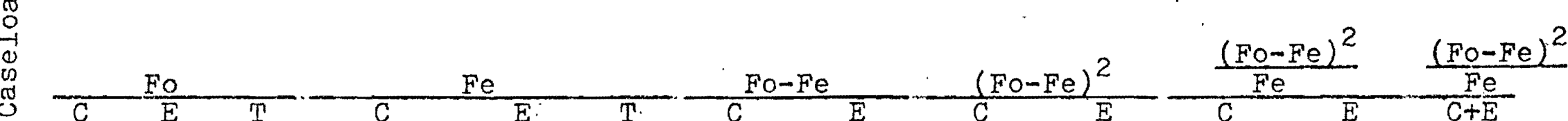

$2.10929 \quad 138 \cdot 112.27: 25.73 \cdot 138 \cdot-3.27 \cdot+3.27 \quad 10.69: 10.69 \quad . .095 \quad .415 .0 .510$

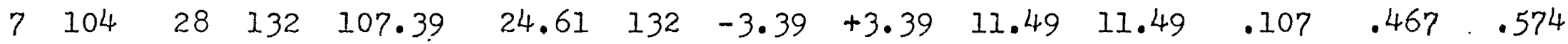

$\begin{array}{llllllllllllll}8 & 98 & 17 & 115 & 93.56 & 21.44 & 115 & +4.44 & -4.44 & 19.71 & 19.71 & .211 & .919 & 1.130\end{array}$

$\begin{array}{lllllllllllll}6 & 46 & 18 & 64 & 52.07 & 11.93 \quad 64 & -6.07 & +6.07 & 36.84 & 36.84 & .707 & 3.088 & 3.795\end{array}$

$\begin{array}{lllllllllllllll}136 & 21 & 157 & 127.73 & 29.27 & 157 & +8.27 & -8.27 & 68.39 & 68.39 & .535 & 2.336 & 2.871 \\ \Sigma & 493 & 113 & 606 & 493.02 & 112.98 & 606 & 25.44 & 25.44 & & 1.655 & 7.225 & 8.880\end{array}$

$\mathrm{x}^{2}=8.88-4^{\circ}$ of freedom - not significant at .05 level

Caseload

$\begin{array}{llrll}2 & X_{2}^{2} & .510 & \text { Not significant at } .30 \text { level of confidence } \\ 7 & X_{2}^{2} & .574 & \text { Not significant at } .30 \text { level of confidence } \\ 8 & X_{2} & 1.130 & \text { Not significant at } .20 \text { level of confidence } \\ 6 & X_{2} & 3.795 & \text { Not significant at } .05 \text { level of confidence } \\ 3 & X^{2} & 2.871 & \text { Not significant at } .05 \text { level of confidence }\end{array}$


II. PERSONALITY FACTORS techniques suggested in the CPI manual. The manual suggests a particular format to be used in analysing the results. The first procedure has been termed an analysis of general profile fluctutation (8). An individual's overall scores are considered in making a general assessment, The manual states that if the majority of scores are above the mean, that individual can be said to be "functioning effectively both socially and intellectually." Conversely, if the majority of scores are below the mean, the individual could be having "difficulties in interpersonal adjustment:". " Table 4 gives a breakdown of each worker's scores above, below and on the mean of fifty.

By using the CPI manual, we found that the majority of the workers manifested no dysfunctional features, although workers three and seven could possibly be having some difficulties.

The next procedure was termed the notation of differential elevation of the four groups of scales (9). Here we looked for high- and low-scale group scores, which indicate strengths or weakness in various areas:

Class I: High scores in this area indicate highlydeveloped social skills. Iow scores indicate poorly developed social."skilis. 
Class II: High scores in this area indicate a high capacity for responsibility, socialization, maturity, and interpersonal structuring of values. Low scores indicate low capacities in these areas. Class III: High scores in this area indicate strong academic drives. Low scores indicate weak academic drives.

Class IV: High scores in the area indicate highly developed intellectual and interest modes. Low scores indicate the opposite.

Table 5 is a breakdown of the individual workers! scores in each of the four classes. "High" indicates scores above the fifty-percent mark, which is the mean. "Low" indicates scores below the mean of fifty percent.

Table 6 is a statistical report of how the group as a whole scored on each scale on the CPI. High and low scores are indicated, as well as the group average and standard deviation. From Table 6 we determined that scores above the mean of 50 totaled 12 ; , while scores below the mean tataled. $6 . \therefore$. Furthermore, all scores fell within standard score ranges of:" 30 to 70 with the mean being 50, thus indicating no dysfunctional characteristics as specified: by the CPI for the group. The scale Ai, achievement via independence, attained the highest group mean of 60.8 . 
TABLE IV

\section{- GENERAL PROFILE OF CPI FACTOR SCORES}

\begin{tabular}{cccc} 
WORKER & NO. OF SCORES & $\begin{array}{c}\text { NO. OF SCORES } \\
\text { BELOW MEAN }\end{array}$ & $\begin{array}{c}\text { NO. OF SCORES } \\
\text { ON MEAN }\end{array}$ \\
\hline 1 & 10 & 8 & 0 \\
2 & 7 & 6 & 5 \\
3 & 7 & 9 & 2 \\
4 & 11 & 6 & 1 \\
5 & 14 & 4 & 0 \\
6 & 11 & 6 & 1 \\
7 & 4 & 14 & 0 \\
8 & 17 & 1 & 0 \\
9 & 13 & 5 & 0
\end{tabular}




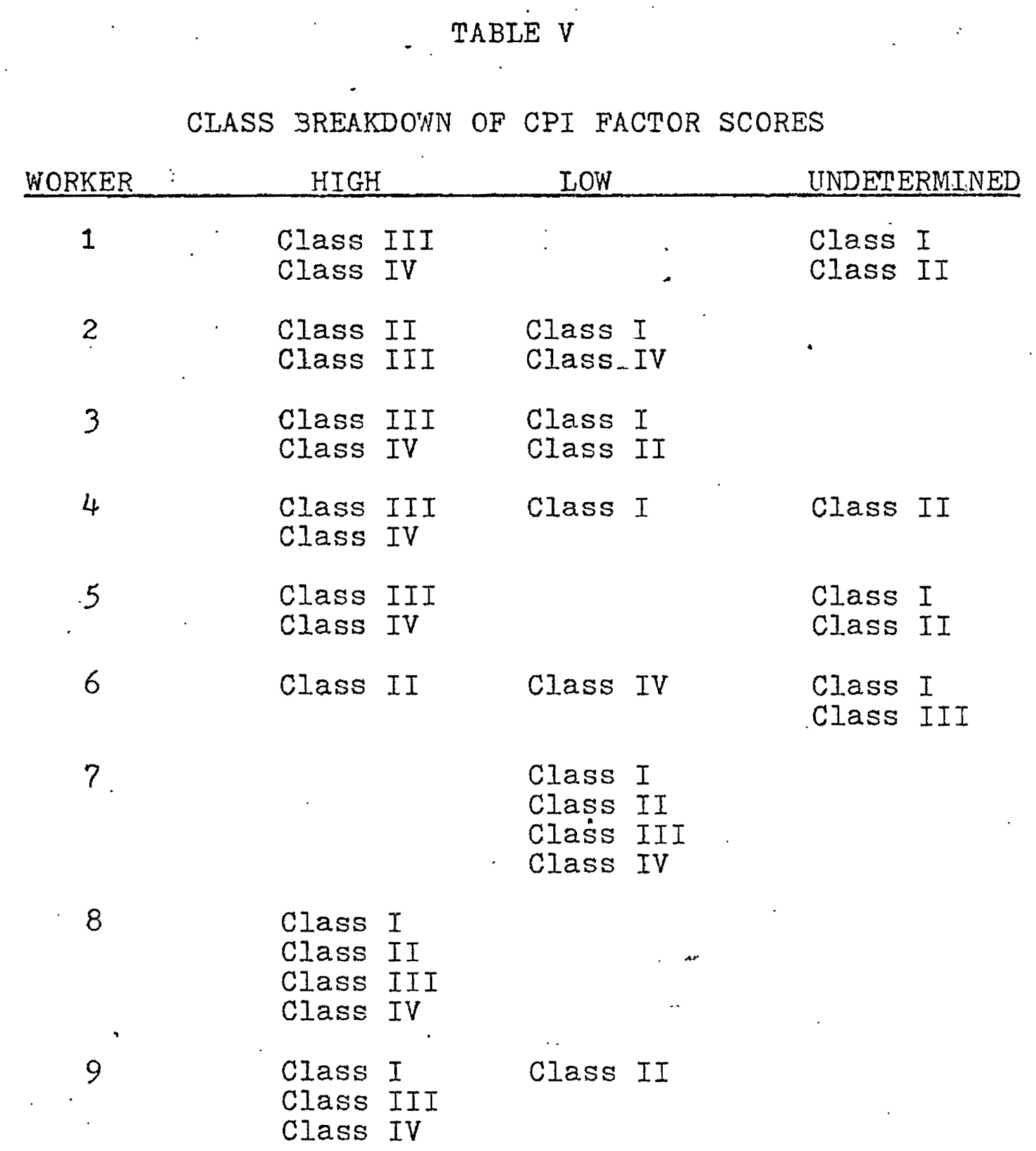


TABLE' VI

GROUP SUMMARY STATISTICS

C.P.I.

Variable

Do

Cs

Sy

$\mathrm{Sp}$

sa

$\mathrm{Wb}$

Re

So

Sc

To

Gi

$\mathrm{Cm}$

Ac

Ai

Ie

PY

Fx

Fe

Hig

69

66

64

56

65

60

58

64

64

62

60

61

75

74

75

73

70
Low

45

33

38

32

36

35

41

33

44

48

35

33

34

42

40

43

33

41
Mean

52.3

48.4

48.1

50.1

48.3

52.7

49.3

49.4

55.7

55.2

51.6

49.8

51.6

60.8

55.7

57.9

56.0

52.9
Standard

Deviation

5.38

11.2

9.57

10.5

6.84

9.23

7.60

8.32

7.35

6.80

8.40

7.69

8.00

9.92

10.1

11.8

13.6

8.62 


\section{WORK SAMPLING}

Table 7 reflects the mean percentages and standard deviations of observations for each group of activities. The reader should note that the percentages add up to nearly $100 \%$ only in the communication activity and work activity areas. Communicative intentions were tabulated only if the worker was actually communicating in some way at the time she was observed.

The most striking figure from the table is that workers spent over half $(55.17 \%)$ of their time in activities not involving communication. This result is remarkable mainly in that previous to the study, both unit workers and the supervisor estimated that about $80 \%$ of workers' time is spent communicating--mostly on the phone. In actuality, all phone calls accounted for about $12 \%$ of workers' time. The item, reassuring and ventilating, is of interest for its low total, reflecting that these workers invested little time in communication usually associated with service functions, i.e.,. dealing with: emotions and feelings, either in others or in themselves. It was decided to disregard correlations with that item because of the low total. The low totals for the item, responding to others, the item office interviews, and the item letter wri-: ting, were similarly disregarded.

Table 8 reflects significant (at least 5\%) correlations between all remaining fifteen work and communication activities. 
WORK SAMPLING SUMMARY STATISTICS

\begin{tabular}{|c|c|c|}
\hline Activity & Mean $:$ & $\begin{array}{l}\text { Standar } \\
\text { Deviati }\end{array}$ \\
\hline (Work Activities). & & \\
\hline Interpretation & 19.11 & 7.67 \\
\hline Financial Manipulation & 19.42 & 5.13 \\
\hline Verification & 12.82 & 4.92 \\
\hline Referrals to Others & 5.40 & 3.08 \\
\hline Housekeeping and Filing & 13.58 & 5.15 \\
\hline Education & 10.00 & 5.28 \\
\hline $\begin{array}{l}\text { Personal Time } \\
\text { (Communicative Intent) }\end{array}$ & 14.70 & 3.49 \\
\hline Passing Information & 25.57 & 3.75 \\
\hline Instructing and Directing & 9.58 & 2.05 \\
\hline Reassuring and Ventilating & 2.13 & 9.50 \\
\hline $\begin{array}{l}\text { Responding to Messages } \\
\text { (Communication Activities) }\end{array}$ & 2.35 & 1.03 \\
\hline Phone Clients & 6.53 & 1.97 \\
\hline Phone Others & 5.81 & 1.94 \\
\hline Field Interviews & 7.69 & 2.64 \\
\hline Office Interviews & 3.14 & 1.20 \\
\hline Conferences & 8.94 & 2.83 \\
\hline Meetings & 7.82 & 3.60 \\
\hline Letter Writing & 3.83 & 1.15 \\
\hline No Communication & 55.17 & 3.21 \\
\hline
\end{tabular}


TABLE VIII

\section{CORRELATIONS OF WORK SAMPLING ACTIVITIES}

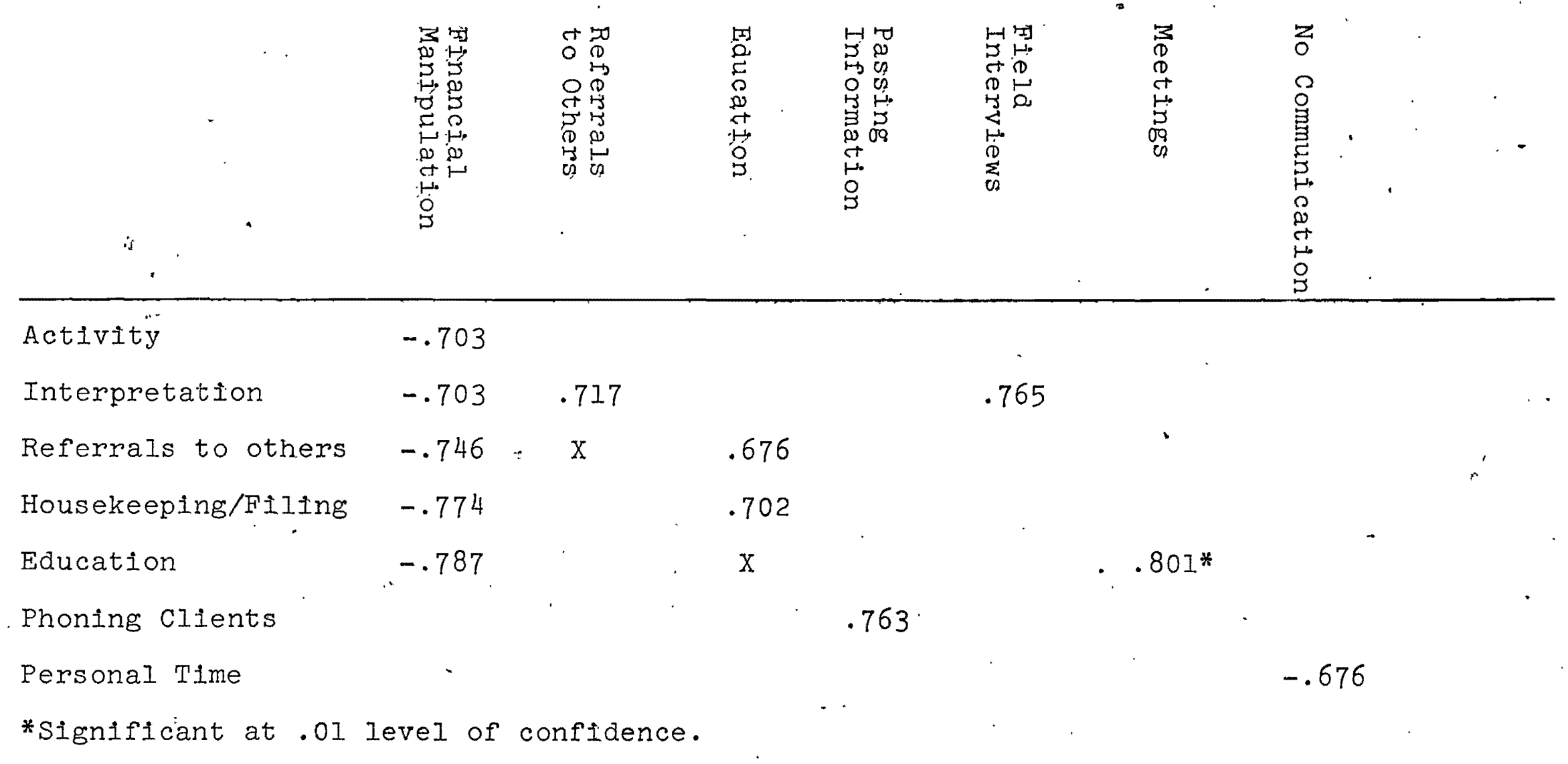


The reader should note that these correlations are between activities at which the workers spent at least $5 \%$ of their time. The negative correlations with respect to Financial Manipulation indicate that workers performing numerous paperwork functions, budget changes, late check actions, etc., did not do so as a result of interpretation, referring, and coordinating with others, or performing general office functions. In addition, time devoted to staff development (the item Education) seems to be inversely related to Financial Manipulation. With respect to Education, a high positive correlation was found with time spent in meetings, as one would expect, given that staff development occurs in meeting settings. Education also correlated positively with Housekeeping Functions, and Referrals to others, perhaps a result of the stress in staff development upon handling paperwork and CSD referrais.

In general, we found that data from specific work activities, behaviors not necessarily involving communication, were more useable than the communication categories and communicative intent categories. The totals of the former were larger, and therefore of greater significance. There were generally more significant correlations, both with other activities and with CPI scores. The only exception regarding specific work activities was in the category we labeled Verification. Although workers spent a mean of nearly $13 \%$ of their time (see Table 7) in verification activities, there were no significant correlations with other activities or CPI scores. 
IV. CORRELATIONS OF WORK SAMPLING DATA AND CPI SCORES

Table 9 reflects significant (at least 5\%) correlations between work activities and CPI factor scores. Of the eighteen personality factors measured by the CPI, ten were found to have significant correlations with the most frequent activities engaged in by the workers. In terms of significance, To (Tolerance) seemed to be one of the most useable scores-two correlations were found at the 5\% level (with Referrals to others and Education), and two others were significant at the 1\% level (inversely with Financial Manipulation and positively with Housekeeping and Filing). The other most useable CPI factor was So (Socialization). This factor correlated positively with Financial Manipulation, and inversely with Housekeeping and Filing, Education, and Meetings. 
CORRELATIONS OF WORK ACTIVITIES AND C.P.I. SCORES

Work Activity

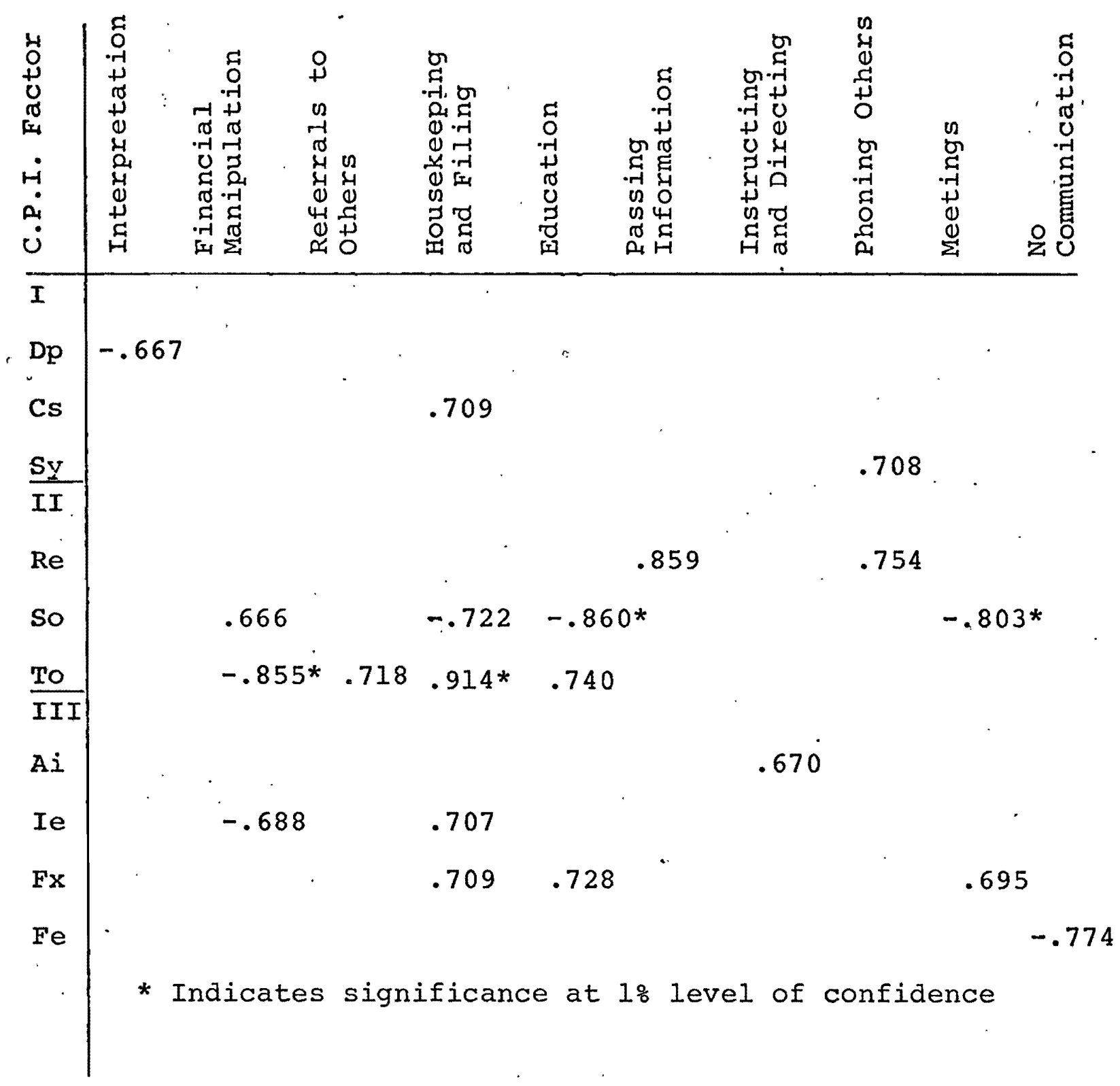




\section{- CONCLUSIONS}

We were unable to find a significant difference in the number of errors located by case reviewers with different skills and levels of experience. We were unable to determine significant differences in the amount of errors found in the five caseloads reviewed. Therefore, we conclude that, given our method of case review, no relationship has been demonstrated linking personality factors as identified by the CPI and work practices with error rates. Our findings substantiate a null hypothesis that no relationship exists between error rates and worker-related variables. However, our findings did establish relationships between personality characteristics as measured by the CPI and work activities for the nine workers studied.

Ten CPI factors were correlated with work activities. The most relevant work activities were those not necessarily relațed to communication with others. More specifically, they included Interpretation, Financial Manipulation, Referrals to Others, Housekeeping and Filing, and Education. The only relevant communication activities were Passing Information, Instructing and Directing, Phoning Others, and Meetings. Most of the significant correlations occurred in non-communication activities. We conclude that, given our present method of investigation, that the CPI can be used as a general pre- 
dictor of some specific work activities. Only a few significant correlations existed between CPI scores and activity involving strictly communication with others, however, We are led to conclude that the CPI is less relevant a predictor of communication activity.

In designing the time study phase of. this project and in attempting to analyze obtained data, we learned that the workers' jobs are highly complex. Specifically, verification activity at which workers invested nearly $13 \%$ of their time, failed to correlate significanly with either any CPI factor or any other activities. We conclude that activities subsummed under the heading Verification are largely autonomous functions in this unit of workers. Assuming that such activities have the most bearing upon error rates (a point often stressed throughout PWD), our findings of no correlations in this area may lend further substantiation to a null hypothesis that no relationship exists between work activity and error rates. 
V. IMPLICATIONS AND RECOMMENDATIONS

Many of the implications we see and recommendations we are making here are generalized to the entire oregon state Public Welfare system. We recognize the risk in making such generalizations based upon observation and data collected from five caseloads and nine workers at a single branch office. The back ground of two of the research team members in agency offices in two other counties may render our statements less presumptuous. Our main point here is not to belabor oür claim to authority, however, but to stress that what we say is tentative and needs similar research on a larger scale in other areas of the state.

Although our study did not investigate causes of high error rates in grants being provided to clients, our experience leads us to speculate in some areas. One possible. reason for the high error rate is lack of appropriate training for.WA's in how to review eligibility factors. At the time of case review, the WAW's should know how to locate significant information contained in the case record, how to gain - information during the home interview, and how to verify information. The verification process should continue until the worker is fully satisfied that the grant:amount:is within PWD standards.

The workers studied in this project had diverse educa- 
tional and work histories. They also had differenct personalities and work habits. The error rates, however, did not vary significantly despite these individual differences. This lack of significant variation in error rates leads us to speculate that the existing training programs, formal and in-service, may have reduced the effect of individual worker differences upon error rates. If this be true, the areas stressed in current training have had some leveling effects in job performance of the WA''s. Perhaps PWD needs to look at the - aim of its training programs, rather than focus on the workers (as some of the workers feel currently occurs) in its attempt to improve accuracy in assistance grants.

According to the PWD Quality Control Reports, a trend toward reduced agency-caused errors has existed since october of 1971 (11). This reduction occurred while client-caused errors increased. The client, then, rather than the assistance worker, is the major source of the errors. We suggest even more stress on the "prudent person" concept and a re-evaluation of the presumptive eligibility or declaratory statement method of assessing initial and ongoing eligibility. Specifically, we question whether presumptive eligibility is a policy which is fiscally sound in an agency which stresses efficiency and accuracy.

Again, at the risk of generalizing to the total state welfare system from our experience at the East Multnomah County office, we speculate a need for objective, statisti-cally reliable research on error rates to be carried out at 
the branch office level. We feel the expertise of Welfare Specialists in the area of eligibility might best be utilized by providing training for them on a statistically sound, objective model for sampling and systematically reviewing cases for errors.

During the process of this study we were provided access to materials generated by the PWD Quality Control Unit. In addition, we questioned how the material was used. Our understanding is that information about branch office errors is extracted from this state-wide sample and is used to determine how efficiently each branch office is functioning. If this be true, then one should question the appropriateness of this use of data obtained. Error rate data, as now collected, is meaningful only when it remains in the total state-wide sample. The practice of "lifting" the data would not be necessary if sampling were done at the branch office level.

After reviewing material from the state Quality control Unit, we feel more attention should be given to variables operating during the time periods covered by those reviews (usually six-month periods). For example, the most recent review report available to us (April - August 1973), covered a different time period than previous reports. Formerly, the report period was usually from January through June or July through December. During the Arril - August 1973 report period, elements affecting the clients (such as no school for the summer, greater employment opportunities, greater likelihood for mobility, etc.) occurred which were captured in the 
same report period for the first time. Previously, the summer months had been divided between two reporting periods. This difference in report periods would dictate a need for caution when comparing the results of this Ap.il - August review with those previously generated. Indeed, we question if any meaningful information could be obtained when making a direct comparison between the April - August report and those covering different time frames. Additional variables are those of the policy and procedural changes which occur between the beginning and the end of a report period. We believe the impact of the individual changes cannot be felt when Quality Control reports are generated on a six-month basis. The implication of this practice is obvious. The PWD cannot know which changes are effective in reducing ineligibility, underpayments, and overpayments.

Quality control research at the branch office level could be designed to provide feedback to the workers on $a$. monthly basis, reflecting impact of policy as well as seasonal variations in factors affecting the clients. This monthly feedback to the branch offices has been previous]y suggested by an agency-generated study (12). Workers could be alerted as to what problems to watch for in the next month rather than learning about the sources of errors up to six months after their occurrence.

Although the review process in East Multnomah County located fewer errors than those identified by state Quality Control, as reflected in the unit's reports, they are not 
Significantly lower in a statistical sense. Had the East Branch reviewers continued to investigate the twenty-ejght cases which were closed at the time of review, related to the review process, the errors located may have more closely approximated those of the state Quality Control Unit. Additionally, the reviewers were not as well trained as the Quality Control personnel. One reviewer was a ninety-day temporary employee and another had less than two years' experience with the agency. Most of the reviewers had other duties which - may have deterred them from operating at maximum efficiency while performing case reviews. Yet, the facts that no significant difference could be found between state Quality Control and branch office error discovery rates leads us to consider the idea of decentralizing state Quality Control staff, shifting the responsibility for quality control to the branch office level, or a combination of state and branch office quality control. Possibly federal requirements or cost-benefit considerations would contraindicate such a move. Were these limits not the case, however, we believe. that cases sampled in error could easily be eliminated at the branch office level, rendering results more meaningful. Currently, sampling cases in error is a problem limiting the usefulness of state Quality Control reports. In the reports generated by PWD Quality Control, it is not clear how the sampling error is compensated for in preventing a bias in the sample. Our attempts at measuring worker performance via the time study method is preliminary. Yet, we were encouraged 
with the results, and believe the PWD should consider further development of the time study approach to measure performance.

We recommend that PWD set performance objectives for WAW's in terms of measurable and specific behaviors and determine the implications of additional responsibilities prior to state-wide implementation. In this way, as additional demands are made of WAW's, data would be available upon which. to predict which areas of current functioning would be affected or, if indeed, whether caseload sizes should be adjusted. The performance objectives could be modified according to the changing needs of the system. Based upon our own results, we believe the likelihood of workers meeting such objectives could be predicted by using standardized personality tests such as the CPI. Also, the time study method could be utilized as an objective method of assessing a worker's performance.' As an example, using the results of this study, were PWD to need workers who tend to be meticulous in housekeeping and filing types of activities, they might screen for applicants with a high capacity for tolerance as measured by the CPI. If workers who are sociable and friendly are desired, stress might be placed on the sociability component of the CPI.

The CPI is a standardized test unrelated to PWD and its services. However, despite the fact that this study has been the first in this state to measure WAW performance against a standardized instrument of demonstrated reliability, we note the high number of significant relationships we found between 
its scores and our design for measuring worker behavior. We speculate that any limitation in the number of significant correlations is a weakness in our design rather than in the CPI, and believe that further development of objective techniques of measuring WAW performance would increase the validity and reliability of the designs.

This study was a preliminary attempt to find some of the factors which could have an effect on error.rates. We believe the primary limitation was in the small number of caseloads reviewed for error rates. We hope that the results we obtained, that of personality factors and work practices having no significant affect on error rates, will stimulate PWD to investigate the relationship between these factors. The results obtained from the time study and the personality inventory were encouraging. We feel our efforts can contribute to a theoretical base needed by PWD to achieve that agency's goal of a greater accuracy in grant expenditures. 


\section{A SELECTED BIBLIOGRAPHY}

1. Public Welfare Division Proposed Objectives, 1973-74, \#1.

2. California Personality Inventory Manual, Gough, Harrison G., Consulting Psychologists Press, Inc., 1957.

3. CPI Manual, pp. 10 and 11.

4. Heiland, Robert E. and Richardson, Wallace J., Work Sampling, McGraw-Hill, New York, 1957.

5. Hill, John G., "Cost Analysis of Social Work Service," in Social Work Research, ed. by Polansky, Norman A., University of Chicago Press, Chicago, 1960, p. 239.

6. Guilford, J. P., Fundamental statistics in Psychology and Education, McGraw-Hill, New York, 1965, p. 269.

7. CPI Manual, p. 12.

8. Ibid. . ". :

9. Oregon State Public Welfare Division Quality Control Report, April - August, 1973.

10. Ibid.

11. Oregon State Public Welfare Division Performance Standaras Project for Welfare Assistance Workers, April 26, 1972. 
Communication Activity

$\frac{1}{5.33}$

2

$\frac{3}{8.45}$

4

8.00

$\begin{array}{llll}6.58 & 10.45 & 8.16\end{array}$

$\frac{5}{7.19}$

6

$\frac{7}{6.99}$

8

9 Totàs:

office Int, client:

4.67

3.29

.507 .48 5.23

5.13 6.29 0

1. $31 \quad 1.36$ $2.61-\frac{5.76}{1.92}$

$0 \quad .65$ $\begin{array}{llll}4.67 & 9.87 & 6.53 & 12.24\end{array}$

Field Interview: $\begin{array}{rr}9.87 & 6.53 \\ 1.32 & 3.92\end{array}$

etter or Form, Client:1.3

conference, Supervisor:2.00 1.32

.65

.68 $\begin{array}{cr}0 & .64 \\ ? .19 & 10.90\end{array}$ 1.40 $\begin{array}{ll}3.90 & 5.10\end{array}$ $4.55 \quad 3.18$ 1.40 $3.25 \quad 3.82$ 1.30 $\frac{3.82}{0}$ $\frac{6.52}{5.70}$ 5.79 6.29 5.84 5.73 $.65 \quad 2.56$ 4.20 $\frac{3.27}{1.96} 1.92$ $.20 \quad 1.30$

$\begin{array}{ll}0 & 2.61\end{array}$ Co-worker: 6.67 2.89 5.88 .68 .96

- Clerk/others $.67-1.3 ?$

Unit Meetjne:

Group Meeting: .67 3.05 1.31 2.04 . 5.88 7.05 3.50 $2.60-1.91$ $2.60 \quad 3.18 \quad 1.98$ 1. 31 1.92 9.09 $4.57 \quad 6.12$ $\begin{array}{ll}1.26 & 1.92\end{array}$ .70 $\begin{array}{lll}1.95 & 8.25 & 1.76\end{array}$ $1.95 \div .0 \%-\frac{0.08}{1.10}$ $0 \quad 4.5$ 5.13 3.50 105 6.2 12.95 2.55 2.34

Intent of Communication: 1

Information:

Verification:-

Reassurance: 2 2 34 $4 \quad 5$ 4.49 2.64 6 7 56.4 4956.05

56.19

Instruction:

Direction: 3.33 $\frac{1.33}{5.33}$ 9.82 $20.26 \quad 15.65$ 16.99 8.59 5.38 $\begin{array}{lrr}8 & 9 & \text { Tot. }\end{array}$

$\begin{array}{r}1.33 \\ \frac{5.33}{4.00} \\ \hline 6.00\end{array}$
.66 4.5 6.00

Clarification:

ventilation:

Response to Message: .67 2.63 $\begin{array}{llll}6.53 & 6.12 & 7.19 & 7.05\end{array}$ 7.69 $5.19 \quad \frac{3.18}{3}$ 1.40 7.69 $1.96 \quad 2.04$ .66

Other: 1.311 .36 $68-\frac{2.61}{1.96}$

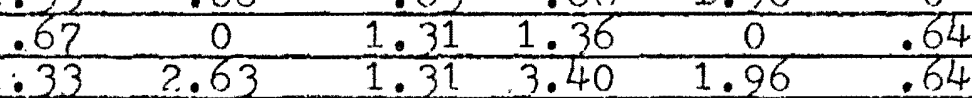
1.28 2.80 5.8 .64 .88

Specific Activity: $\begin{array}{llll}1 & 2 & 3 & 4\end{array}$ $\begin{aligned} & 4 \\ & 12\end{aligned} \quad 5.50-7.05$

\begin{tabular}{lllll}
64 & 1.40 & 1.30 & .64 & .66 \\
\hline
\end{tabular}

Transportation:

Handwriting - Let,ter:

Writing Form letter $3 \frac{4}{50}-6.1$

7
7 8 9 Tot.

Reading Manua? :1.00 2.63

Filing:

403B Action:

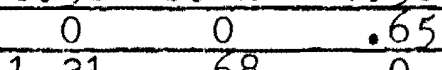

$\frac{.05}{0}$ 1.40 1. 31 $65-\frac{0}{1.28}$

\begin{tabular}{rr}
40 & 0 \\
\hline
\end{tabular}

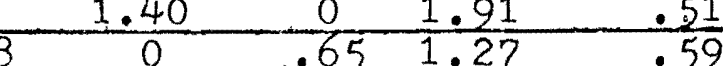
$\begin{array}{lll}1.31 & 5.44 & 3.92\end{array}$ $1.96 \quad 8.84 \quad 35$ .64 $6.99-\frac{.6}{3.25} \quad \frac{1.27}{1.27}-2.93$ $\begin{array}{llll}4.20 & 0 & 2.55 & 2.34\end{array}$ $\begin{array}{lllllllllllll}4.67 & 2.63 & 2.61 & 1.36 & 3.27 & 4.49 & 1.40 & 3.90 & 3.82 & 3.15\end{array}$

437 Action (late ck): $00 \quad 000$ 409 Action (review): 1.33

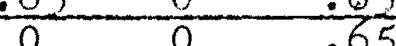

$859 \mathrm{~A}$ Repoty (earnings): 000000.65

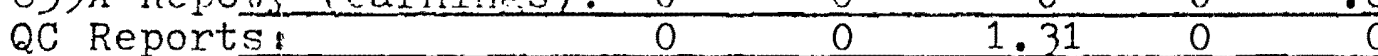

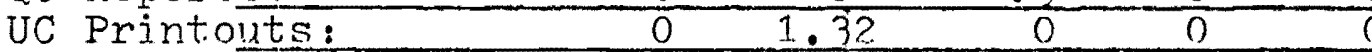

WIN Referra]:

.66

$0 \quad 1.36 \quad 0$

0

$\begin{array}{ccccc}0 & 1.40 & 0 & 0 & .22 \\ 0 & 3.50 & 0 & 0 & .51 \\ 0 & 0 & 0^{2} & 0 & .15 \\ .64 & 1.40 & .65 & 0 & .59\end{array}$

$\begin{array}{cccc}0 & 0 & .04 & .27 \\ .20 & 0 & 0 & .37 \\ .09 & 5.84 & 2.55 & 5.57 \\ 0 & .65 & .64 & 1.76 \\ 1.40 & 0 & 0 & .22 \\ 3.50 & 0 & 0 & .51 \\ 0 & 0 & 0 & .15 \\ .40 & .65 & 0 & .59\end{array}$


WORKER

Spec. Acts.. Cont. WRD ReferraI: Transfer Action: Openings:

Closures:

School. Al Iowance:

405B Allowance:

Check $403 \mathrm{~B}$ w Salem:

7.33

Thinking:

2.00

$\begin{array}{cc}1 & 2 \\ .00 & 1.97\end{array}$

3

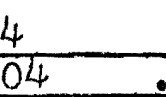
.65 $65-1.28$

$\begin{array}{cccccccccc}.00 & 1.97 & 1.96 & 2.04 & .65 & 0 & 0 & 0 & 1.91 & 1.24 \\ .33 & 0 & .05 & .68 & .65 & 1.28 & 0 & 0 & .64 & .81 \\ 0 & 0 & 0 & 0 & .65 & 0 & 0 & .65 & 1.27 & .29 \\ 0 & .66 & 2.61 & 2.04 & 0 & .64 & 0 & 0 & .64 & .73\end{array}$
8 9 Totals

Service Function:

CSD Referral.

1.33 $\begin{array}{llll}.66 & 2.61 & 2.04 & 0\end{array}$ .64 $0 \quad .64$

$\begin{array}{ccc}0 & 0 & 0 \\ .66 & .65 & 0\end{array}$
.66 .65

.66

$0 \quad 0$

$0-65$

$64 \quad .70$

.70

$\begin{array}{cc}.65 & .64 \\ 0 & 0 \\ 0 & 0\end{array}$

0

0

$.64 \quad . ?$

Other Referral:

Staff Develonment:

$1.31 \quad .68$

68

.64

20

.615 .44

0

5.23

0

$0 \quad 0$

0

.2

Elig. Interpretation: 2.67

Med. Policy Interp.

2.67

.66

.657 .48

$.65-\quad .64$

6.99

0

.64

$\begin{array}{llll}6.99 & 1.95 & 5.10 & 3.96 \\ 1.40 & .65 & 3.82 & 1.10\end{array}$

0 1.96

0.65

$0-\frac{1.40}{4.20}$

.65 $\begin{array}{rrrrr}.64 & 1.40 & 1.30 & .64 & .81 \\ 3.20 & 7.69 & 15.58 & 9.55 & 7.11\end{array}$

.64

1.03 $3.29 \quad 6.53 \quad 7.48$

7.84

3.25

$4.52 \quad 5.44$

4.57

$2.05-2.10$

Collatera] Calls: $\quad 2.00$

.32 $0 \quad .68$

Food Stamps

$\begin{array}{ccccc}\text { Other Memos: } & 0 & 0 & 0 & .68 \\ \text { Misc. Office Act.: } & 4.67 & 5.92 & 11.11 & 10.20\end{array}$

$\begin{array}{llll}.00 & 1.97 & 3.26 & 1.36\end{array}$

Eligibility Det.: 4.67

459 Action:

Active Iistening:

.67

$\begin{array}{rrr}5.92 & 11.11 & 10.20 \\ 6.58 & 5.88 & 13.60\end{array}$

.68

$\begin{array}{ccccc}4.57 & 2.56 & 2.80 & 1.25 & .64 \\ 0 & 0 & 2.10 & .65 & 1.27\end{array}$

$\begin{array}{rr}.70 & .0 \\ & 0\end{array}$

$65 \quad 5.10$

4.03

$1.95 \quad 0$

2.10

.65

$\frac{1.27}{3.18}$

5.23

$23-8.33$

$0 \cdot 2.56$

$.52 \cdot .68$

Grant. Recomp.: I.33

Coffee Break:

Lavatory Brea:

Vacation:

Comp. Time:

Sick Leave:

"X" - Time.

Personal. Time:

$\begin{array}{lll}1.33 & 0 & 1.31\end{array}$

0

3.2

$56-1.40$

10.39

$.55 \quad 8.92$

$1.40 \quad 7.30$

$\begin{array}{rrrrrr}.27 & 1.28 & 2.80 & 1.95 & .64 & 2.12 \\ 0 & .0 & .70 & 1.30 & .64 & .51\end{array}$

$\frac{92-7.18}{0}$

.70

$\begin{array}{rrrr}.20 & 1.20 & .64 & .51 \\ 0 & 9.74 & 8.28 & 6.89 \\ 0 & 1.27 & .59\end{array}$

$\begin{array}{ll}65 & 1.36\end{array}$

.67

$\begin{array}{lllllll}2.50 & 10.45 & 6.12 & 3.27 & 5.72 & 4.20\end{array}$

$5.23-2.48$

$0 \quad 1.28$

$\begin{array}{cccccc}0 & 1.28 & 0 & 0 & 1.27 & .59 \\ 0 & 0 & 0 & 0 & 0 & 1.08 \\ 50 & 3.20 & .70 & 3.25 & 5.10 & 3.15\end{array}$

2.00

2.63

$24.00 \quad 10.53$

$\begin{array}{ll}4.66 & 6.58\end{array}$

other:

$\begin{array}{rr}.66 & 6.58 \\ .67-.66\end{array}$

\begin{tabular}{lll}
.68 & 8.50 & 3.20 \\
\hline
\end{tabular}

.70

$\frac{5.59}{2.80}$

$.65 \quad 0$

$0 \quad \frac{2.01}{0}$

$0 \quad 0$

0.80

.80

$.80-9.62$

1]. 1.9

$\begin{array}{ccc}8.44 & 5.10 & 6.89 \\ 0 & 0 & .37\end{array}$

$\begin{array}{ll}5.19 & 0 \\ & 0.64\end{array}$

Total Worker-

Reported Samples:

$9.33 \quad 24.34$

$18.95 \quad 19.72 \quad 22.88$

$25.64 \quad 11.89$

17.5311 .56

.64

7.25

Total Samples per Worker:

15

152

$153 \quad 147$

153

156

143

154

157

18.02

1365 
See footnote 1. Phone:

Office Inter. Client:

Client

Dav Number---- $\rightarrow$

Field Interview:

Client:

Letter or Form:Client: other:

Conference: Supervisor:

Co wworker:

Clerk:

Unit leeting:

Group Meoting:

No Communication:

Intent of Commanication:

Ser footnote 2. Information:

Verifáca tiom:

Reassurance:

Instruction:

Direction:

Clarification:

Ventilation:

Response to message:

Other:

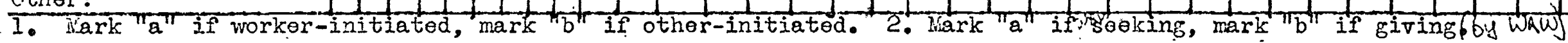
Other Activities:

Transportation:

Dictating:

Handwriting letter:

Writing form letter:

Reading Case Haterial:

Reading Manual Material:

Filing:

403B Action (budget)

437 Action (lato check):

138A Action (lost ${ }^{-1}$ ):

409 Action (roviow):

LOSA Narrative:

859A Report (earnings)!

475A Action (appl.):

470C Action (taxes):

QC Reports:

UC Printouts:

WIN Referral:

$+50100$

\section{T.}

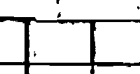

\section{\begin{tabular}{ll|l|l|l|l|l|l|l}
\hline & & & & & & & \\
\hline & & & & & & & \\
\hline & & & & & & \\
\hline
\end{tabular}}
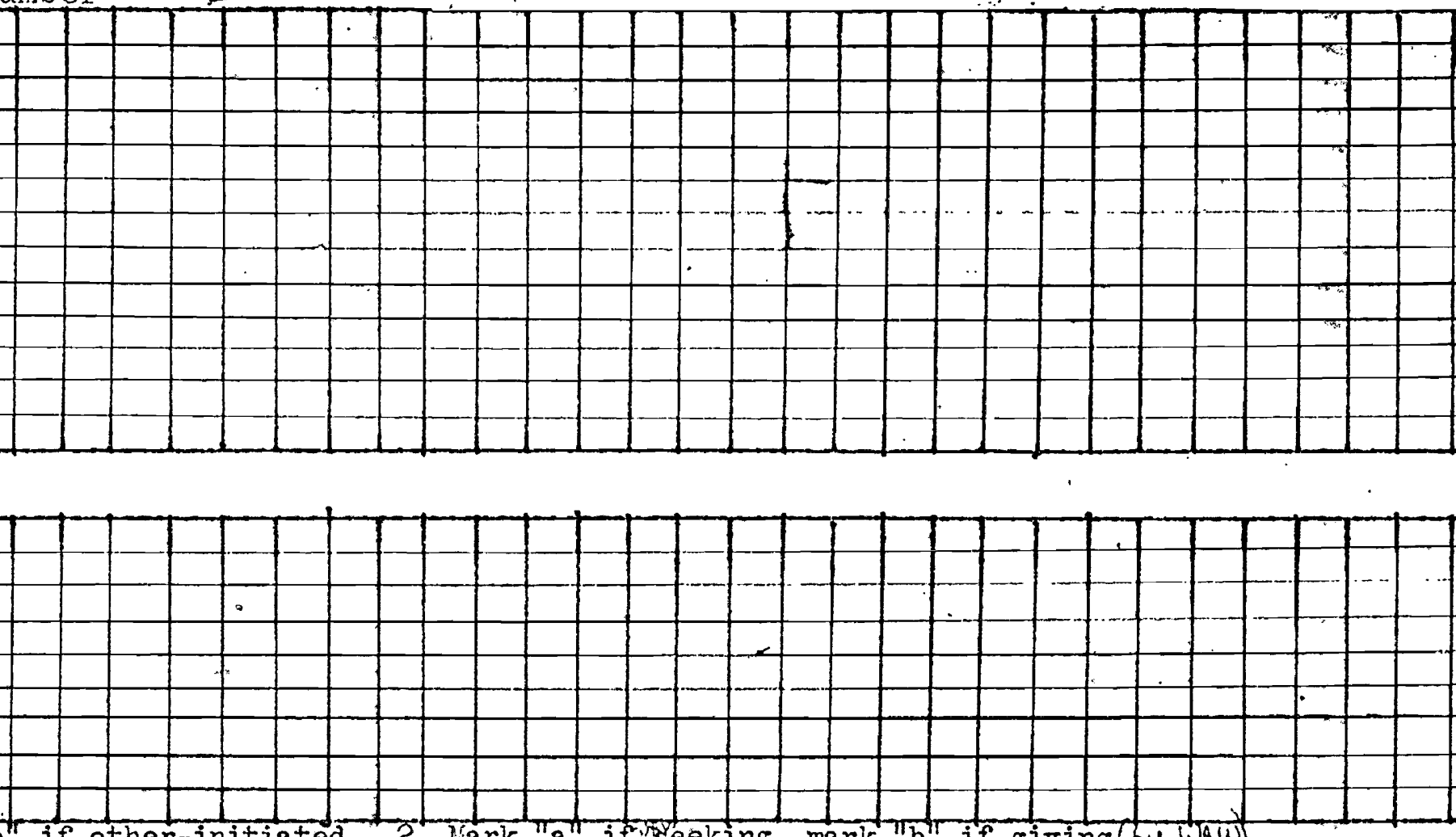

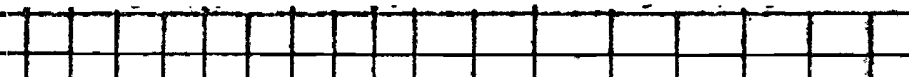

\begin{tabular}{llllll} 
& & & & & \\
\hline
\end{tabular}

:

\begin{tabular}{llllllll} 
& & & & & & & \\
\hline & & & & & & \\
\hline
\end{tabular}

$+$


